\title{
Decreased Serum Paraoxonase 1 Activity and Increased Serum Homocysteine and Malondialdehyde Levels in Age-Related Macular Degeneration
}

\author{
Orhan Ates, ${ }^{1}$ Sedat Azizi, ${ }^{1}$ H. Hakan Alp, ${ }^{2}$ Ahmet Kiziltunc, ${ }^{2}$ Sukru Beydemir, ${ }^{3}$ \\ Emine Cinici, ${ }^{1}$ Ibrahim Kocer ${ }^{1}$ and Orhan BaykaL ${ }^{1}$ \\ ${ }^{1}$ Department of Ophthalmology, Medical Faculty, Atatürk University, Erzurum, Turkey \\ ${ }^{2}$ Department of Biochemistry, Medical Faculty, Atatürk University, Erzurum, Turkey \\ ${ }^{3}$ Department of Chemistry, Science and Arts Faculty, Atatürk University, Erzurum, Turkey
}

Age-related macular degeneration (AMD) is one of the most common causes of vision loss. AMD has been classified into two forms: atrophic and exudative forms. The exudative form is associated with choroidal neovascularization of the subretinal macular region, resulting in a sudden loss of central vision. However, the exact cause of AMD remains unknown. Several risk factors have been postulated, including smoking, atherosclerosis, and low levels of antioxidant enzymes. Malondialdehyde (MDA), a lipid peroxidation product, is used as a marker of oxidative stress. Paraoxonase 1 (PON1) metabolizes lipid peroxides and prevents oxidation of low-density lipoprotein. Increased levels of homocysteine may cause vascular endothelial injury by releasing free radicals. The purpose of this study is to investigate the relationships between serum PON1 activity and the serum levels of homocysteine and MDA in AMD. Forty patients with exudative-type AMD (63.3 \pm 5 years) and 40 controls (61 \pm 4 years) were assessed in a cross-sectional study. The serum PON1 activity was significantly lower in the patients with AMD than that in the controls $(p<0.001)$. In contrast, the serum levels of MDA and homocysteine were significantly higher in the patients than those in the controls ( $p<0.001$, for both). In AMD patients, significant negative correlation was found between PON1 activity and MDA level $(r=-0.493, p<0.05)$ and between PON1 activity and homocysteine level $(r$ $=-0.557, p<0.05)$. Increased serum homocysteine and MDA levels may be responsible for the decreased PON1 activity in patients with AMD. —— age-related macular degeneration; paraoxonase; lipid peroxidation; homocysteine; oxidative stress.

Tohoku J. Exp. Med., 2009, 217 (1), 17-22. (C) 2009 Tohoku University Medical Press

Age-related macular degeneration (AMD) is one of the most common and irreversible causes of severe loss of vision, including legal blindness, in the elderly population (Van Leeuwen et al. 2003; Feher et al. 2005). AMD has been classified into two subgroups based on clinical and pathological features: atrophic (dry form) and exudative (wet form). Either a central or non-central dry form (also known as geographic atrophy) has a progressive course, leading to the degeneration of retinal pigment epithelium (RPE) and photoreceptors. The exudative form, the most rapidly progressing form of AMD, is associated with choroidal neovascularization of the subretinal macular region, which results in bleeding and/or fluid leakage, and thus, a sudden loss of central vision (Nowak 2006). The pathogenesis of AMD has remained unclear despite intensive basic and clinical research. This may be due to the multifactorial nature of the disease (Cohen et al. 1994; Vingerling et al. 1995, 1996). While the disease is significantly correlated with age, a complex interaction of metabolic, functional, genetic and environmental factors has also been held responsible for the chronically developing changes in ocular structures of the macular region (choriocapillaries, Bruch's membrane, RPE, photoreceptors), all of which may contribute to the onset and final picture of AMD (Wiggs 2007). A better understanding of the etiology and pathogenesis of AMD at the cellular and biochemical level is required to improve treatment and prevent this disease.

Production of free radicals is a continuous process by mitochondrial electron transport enzymes such as xanthine oxidase and aldehyde oxidase, inflammation, xenobiotic metabolism and hyperoxia (Valko et al. 2007). According to the free radical theory of aging, reactive oxygen species (ROS) cause oxidative damage during the lifetime of a subject. The cumulative and potentially increasing amount of accumulated damage has been held responsible for the dysfunctions and pathologies seen in normal aging (Irshad and Chaudhuri 2002). It has been suggested that the central area of the neurosensory retina and the underlying retinal pig-

Received September 12, 2008; revision accepted for publication November 26, 2008.

Correspondence: Orhan Ates, Atatürk Universitesi Tıp Fakültesi, Göz Hastalıkları A.B.D, 25100 ERZURUM, Turkey.

e-mail: orhanates69@hotmail.com 
ment epithelium might be susceptible to the cumulative toxic effects of continued photic damage, and thus, the free radical theory of aging applies especially to AMD (Halliwell 1991). Previous studies suggest that circulating ROS may damage the choriocapillaris and lead to AMD (Baskol et al. 2004). The balance between the generation of ROS and ROS clearance can be disturbed with increasing age, which in turn results in oxidative damage to macromolecules such as lipids and proteins (Beatty et al. 2000). Various cellular functions involving proteins: receptor, signal transduction mechanism, transport system, and enzymes may be affected by in vivo oxidative modification of proteins (Valko et al. 2007). Increased levels of advanced oxidation protein products (AOPP) are unique markers of oxidative stress caused by the oxidative damage to proteins (Irshad and Chaudhuri 2002). Lipid peroxidation products are generated by ROSmediated oxidation of cell membrane lipids (Ohira et al. 2008). Lipid peroxides are used as an indicator of oxidative stress in cells and tissues. Lipid peroxidation products derived from polyunsaturated fatty acids (PUFAs), including reactive carbonyl compounds, among which MDA is the most abundant, are unstable and decompose to from a complex series of compounds. They include reactive carbonyl compounds, among which MDA is the most abundant. Accordingly, MDA measurements are commonly used as a marker of lipid peroxides. Elevated levels of lipid peroxides have been associated with a variety of diseases in both human and model systems (Irshad and Chaudhuri 2002; Valko et al. 2007).

Paraoxonase (PON1), a calcium-dependent esterase, is closely associated with the high-density lipoprotein (HDL) subfraction containing apolipoprotein A-I in human serum. Paraoxonase acts as a catalyst for hydrolysis of organophosphates, metabolizes lipid peroxides and prevents oxidation of low-density lipoprotein (LDL). It is widely distributed among tissues such as the liver, kidney, and intestine. A cysteine thiol group contained by the active site of PON1 is essential for PON1-mediated protection of LDL against atherogenic oxidative damage (Marchegiani et al. 2008).

Exudative neovascular AMD has a degenerative process that causes proliferation of choriocapillaries in the subretinal space (Axer-Siegel et al. 2004). Increased levels of plasma vascular endothelial growth factor, von Willebrand factor, and fibrinogen, as well as increased plasma viscosity in patients with AMD have been reported in several studies. These findings indicate an association of markers of angiogenesis, hemostasis, and endothelial dysfunction with AMD. This hypothesis is supported by the results of the study by Nowak et al. (2005a), which reported an association between AMD and atherosclerosis. High levels of homocysteine result in direct vascular endothelial injury by releasing free radicals, inhibiting glutathione peroxidase and nitric oxide, interfering with clotting factors and lipid peroxidation, all of which modify the vessel wall (Genser et al. 2006; Papandreou et al. 2006). We hypothesized that neovascular AMD might also be associated with elevated plas- ma levels of homocysteine, an apparently independent risk factor for atherosclerotic vascular disease, including coronary and cerebrovascular disease.

Several studies have focused on homocysteine and lipid peroxidation in AMD; however, only one study on the PON1 activity and lipid peroxidation status of patients with active AMD is available (Baskol et al. 2004; Kamburoglu et al. 2006; Seddon et al. 2006; Kaemmerer et al. 2007). In the present study, we investigated the relationship between serum PON1 activity and homocysteine and MDA in AMD.

\section{Materials and Methods}

\section{Patients and Methods}

Forty consecutive patients (18 males and 22 females) diagnosed with exudative-type AMD were assessed in this study. Data regarding age, sex, detailed medical history of hypertension and diabetes mellitus, peripheral, coronary atherosclerotic disease and cerebrovascular events, medication, and smoking habits was obtained. The mean age of the patients was $63.3 \pm 5$ (range 58-72years). Patients with a history of coronary heart disease, cerebrovascular events, neoplastic disease, renal and/or liver failure, vitamin supplementation, smoking habits, retinal vascular disease, and anterior optic neuropathy were excluded from the study. All participants underwent a complete ophthalmic examination consisting of best corrected visual acuity, slit lamp biomicroscopy, dilated funduscopy, and fundus photography with fundus fluorescein angiography (FFA). The control group consisted of 40 healty volunteers whose age and gender similar to the experimental group. The patients with the following characteristics were considered to have AMD based on the results of the FFA. Patients with choroidal neovascularization (CNV) were included in the study group. The written informed consent of all the participants was obtained.

Venous blood samples of the patients and controls were collected in test tubes containing ethylenediamine tetraacetic acid. The samples were centrifuged at $4^{\circ} \mathrm{C}$ and serum MDA levels were measured according to a previously described method (Baskol et al. 2004). This method is based on the spectrophotometric measurement of the color formed during the reaction of thiobarbituric acid with MDA. The concentration of thiobarbituric acid reactive substances was calculated by the absorbance coefficient of the malondialdehyde-thiobarbituric acid complex and expressed as nmol/ml. MDA bis (dimethyl acethal)TBA (thiobarbituric acid) complex was used as a standard. Paraoxanase activity was measured according to a previously described method (Marchegiani et al. 2008). One unit of paraoxanase activity is defined as $1 \mu \mathrm{mol}$ of $\mathrm{p}$-nitrophenol formed per minute. The activity was expressed as a unit per liter of serum (U/l). Serum homocysteine levels were measured by high-performance liquid chromatography, in a masked fashion. Homocysteine values of 5 to $15 \mu \mathrm{mol} / 1$ were considered to be in the normal range, and hyperhomocysteinemia was defined as any homocysteine level above $15 \mu \mathrm{mol} / \mathrm{l}$ (Seddon et al. 2006).

The study was approved by the Research Ethics Committee of Medical Faculty, Erzurum Ataturk University. Each patient signed a purpose-made informed consent form.

Statistical analysis

Statistical analyses were done using SPSS for Windows (version 11.0, SPSS Inc., Chicago, IL, USA). Normality of data was tested by 
the Shapiro-Wilk test and intergroup comparisons were done using the Independent Samples T-test. The degree of correlation was calculated using the Pearson Correlation and $p<0.05$ was considered statistically significant.

\section{Results}

The changes in all parameters are shown in Table 1. The age and gender distributions of the patient and control

TABle 1. PON1, MDA and Homocysteine levels of patients and controls.

\begin{tabular}{lcc}
\hline $\begin{array}{c}\text { Parameters } \\
\text { (Mean } \pm \text { S.D. })\end{array}$ & $\begin{array}{c}\text { Patients } \\
(n=40)\end{array}$ & $\begin{array}{c}\text { Controls } \\
(n=40)\end{array}$ \\
\hline PON1 $(\mathrm{U} / \mathrm{L})^{*}$ & $92.6 \pm 48.2$ & $236.6 \pm 98.0 \mathrm{U} / \mathrm{L}$ \\
MDA $(\mathrm{nmol} / \mathrm{mL})^{*}$ & $6.9 \pm 1.3$ & $4.3 \pm 1.3 \mathrm{nmol} / \mathrm{mL}$ \\
Homocysteine $(\mathrm{mmol} / \mathrm{L})^{*}$ & $11.6 \pm 2.9$ & $9.8 \pm 1.5 \mathrm{mmol} / \mathrm{L}$ \\
\hline
\end{tabular}

Values are expressed as means \pm S.D.

Significant difference between patients and control group, $* p<0.001$

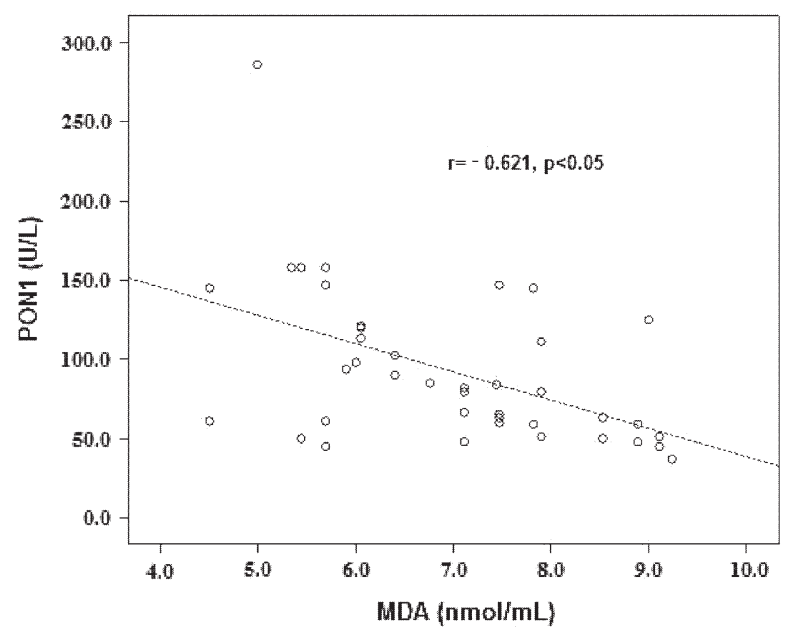

Fig. 1. Correlation between PON1 and MDA in patients.

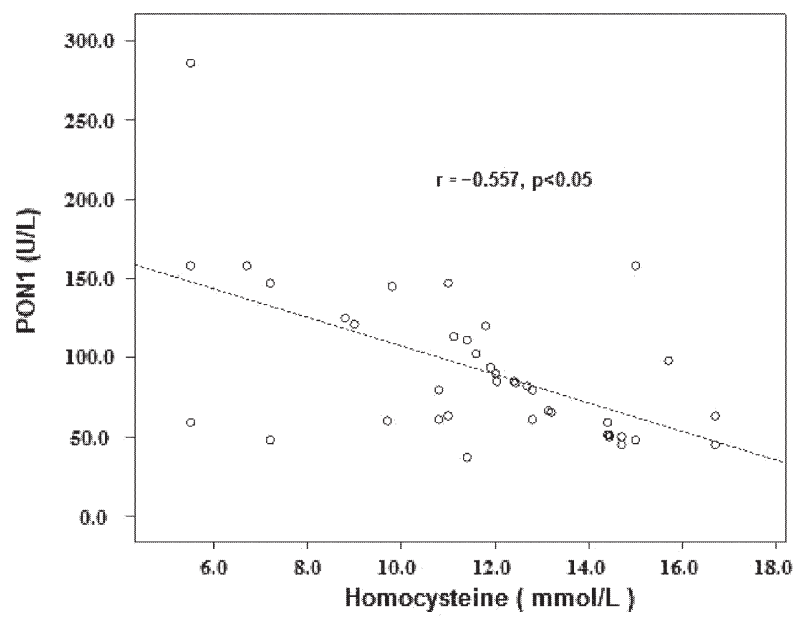

Fig. 2. Correlation between PON1 and homocysteine in patients. groups were not significantly different $(p>0.05)$. There is not any statitically significant difference in each parameter between non-smoking and smoking patients. The mean serum PON1 and MDA levels of the patient group were $92.6 \pm 48.2 \mathrm{U} / \mathrm{L}$ and $6.9 \pm 1.3 \mathrm{nmol} / \mathrm{mL}$, respectively. The mean serum PON1 and MDA levels of the control group were $236.6 \pm 98.0 \mathrm{U} / \mathrm{L}$, and $4.3 \pm 1.3 \mathrm{nmol} / \mathrm{mL}$, respectively. The mean serum PON1 level of the patient group was significantly lower than that of the control group, while the mean serum MDA level of the patient group was significantly higher than that of the control group $(p<0.001)$. The mean serum homocysteine concentration of the patient group was $11.6 \pm 2.9 \mathrm{mmol} / \mathrm{L}$ and was $9.8 \pm 1.5 \mathrm{mmol} / \mathrm{L}$ for the control group. The mean serum homocysteine level of the patient group was significantly higher than that of the control group $(p<0.001)$. The serum PON1 level in patients was significantly negatively correlated with the MDA level $(r=-0.621, p<0.05)$ (Fig. 1). Similarly, serum PON1 activity was negatively correlated with homocysteine levels $(r=-0.557, p<0.05)$ in AMD patients (Fig. 2).

\section{DISCUSSION}

ROS are molecules with an unpaired electron, making them highly reactive. ROS are produced in all tissues during aerobic metabolism and they can also be formed by photochemical reactions (Leibovitz et al. 1980). ROS disturb the protective systems and thus cause lipid peroxidation and cellular damage. They may play a role in the pathogenesis of a number of acute and chronic diseases in addition to AMD (Nowak et al. 2005b; Drobek-Słowik et al. 2007). There are many factors associated with oxidative damage in the eye. The exposure to light throughout life is one of the well-known factors. In addition, polyunsaturated fatty acids have been known to be an important factor in making the eye more susceptible to oxidative damage compared to other organs. The retina is exposed to increased lipid peroxidation by ROS due to its high polyunsaturated fatty acid content (Winkler et al. 1999). Previously, it was shown that excessive ROS production might arise from an imbalance between oxidant and anti-oxidant systems. The attack of ROS on the polyunsaturated fatty acids of cell membranes may induce formation of lipid peroxidation products (Delcourt et al. 1999; Desmettre et al. 2004). In our study, MDA levels were higher in patients with AMD compared to controls. The results of this study are consistent with the results of some previous reports (Young 1998, Evereklioglu et al. 2003).

In the study by Baskol et al. (2006), PON1 activity was lower in the patients with nonexudative-type AMD than in the controls. In another study, Ikeda et al. (2001) reported that the paraoxonase gene polymorphisms might be a possible genetic risk factor for exudative-type AMD. In our study, serum PON1 activity declined in patients with AMD in comparison to the healthy controls. The exact mechanism of the decline of the serum PON1 activity in AMD patients is unclear; however, it may be attributed to an 
increased inactivation of PON1 due to the increased generation of ROS in AMD patients (Ferretti et al. 2007; Isik et al. 2007). Consequently, consumption of PON1 to prevent oxidation results in a decrease of serum PON 1 activity (Gocmen et al. 2004, 2005). It has been found that the protection against lipid peroxidation is achieved by PON1, during which free sulfhydryl groups of PON1 interact with specific oxidized lipids, and thus, PON1 is inactivated (Gocmen et al. 2004). Furthermore, in the present study, oxidized LDL levels were higher in AMD patients than in controls (Kamei et al. 2007). PON1 has been shown to neutralize the harmful effects of lipid peroxides by diminishing covalent linkages between lipid peroxidation products and LDL protein, as well as the accumulating lipid peroxides in LDL (Harangi et al. 2008). Baskol et al. (2006) concluded that the increased ROS levels might cause increased lipid peroxidation, and thus, result in decreased antioxidant PON1 activity and increased MDA levels. They also determined a significant negative correlation between MDA and PON1 activities in the patient group. Similarly, in our study, the patients with exudative-type AMD had lower PON1 activity than the control group. In addition, a significant negative correlation was determined between MDA and PON1 activities. Thus, it can be stated that AMD patients may be much more susceptible to oxidative stress than control subjects because of the increased formation of peroxides or the decreased breakdown of peroxides by PON1. In the light of these results, lower PON1 activity may account for the increased lipid peroxidation and oxidative stress observed in AMD.

Homocysteine is a very reactive molecule, suspected to be the cause of atherosclerosis and heart disease by directly damaging the endothelium or increasing oxidative status. However, the exact mechanism of the damage is unknown (Hankey and Eikelboom 1999). Toxic hydrogen peroxide and hydroxyl radicals are generated during the autooxidation of homocysteine, and these radicals promote oxidative stress (Papatheodorou and Weiss 2007). In experimental studies, various possible mechanisms have been proposed to account for the vascular effects of homocysteine. Homocysteine has a mitogenic activity in vascular smooth muscle cells. This can lead to arterial wall thickening as well as intracellular release of calcium in these cells, and thus increase their proliferation and the mass of extracellular matrix (Ozdemir et al. 2004). Another theory is that homocysteine causes oxidative injury to endothelial cells and enhances the peroxidation of low-density lipoproteins, which in turn promotes the atheromatous process. Increased homocysteine could also increase thrombotic events while inhibiting the expression of thrombomodulin secreted by the endothelial cells to prevent the activation of protein C. Additionally, the activity of factors V and VII and the adhesion of platelets to the endothelium increases. Homocysteine is toxic to the vascular endothelium, which may also account for its association with CNV. Homocysteineinduced damage to the choriocapillaris endothelium can lead to vascular occlusion and neovascularization (Stamler et al. 1993; Jakubowski 1997; Upchurch et al. 1997). According to the findings of the study by Ueland et al. (1993), total homocysteine in serum/plasma increased markedly in patients with cobalamin or folate deficiency, and decreased only when they were treated with the deficient vitamin. Seddon et al. (1994) have demonstrated a relationship between dietary status and the risk of developing exudative AMD. Hence, they found higher homocysteine plasma levels in their neovascular AMD group. This may be a marker of nutritional status. In the present study, patients with exudative-type AMD had significantly higher homocysteine concentrations compared to controls. These results support the study performed by Alvares Delfino et al. (2007). Thus, it may be suggested that homocysteine toxicity to the vascular endothelium may also account for exudative-type AMD pathogenesis. However, it is still not known whether hyperhomocysteinemia is a common response to oxidative stress or whether oxidative stress and homocysteine levels are influenced by a common factor such as genetic mutations. Homocysteine can be converted into homocysteine thiolactone in all cell types; this leads to potentially harmful protein damage by homocysteineylation that may be involved in the pathology of vascular diseases (Evereklioglu et al. 2003). PON1 shows homocysteine thiolactonase activity, which might contribute to the detoxification of this metabolite of homocysteine (Jakubowski 2003). In mice, it has been found that PON1 mRNA is downregulated and there is lower PON1 activity with moderate to severe hyperhomocysteinemia, which is caused by a hyperhomocysteinemic diet or by a genetic deficiency in cystathionine b-synthase (Janel et al. 2004). We found higher serum homocysteine levels in the patients with AMD compared to controls. The higher homocysteine levels were correlated with higher serum MDA and lower PON1 activity.

According to our results, it can be stated that homocysteine may negatively regulate PON1 gene expression in active AMD, which could contribute to lower serum PON1 activity due to enhanced oxidative stress. This hypothesis should also be tested by an intervention aimed at lowering homocysteine concentrations. In general, our study demonstrated a lower PON1 activity in patients with AMD and a negative correlation of levels of MDA with PON1 activity. Moreover, high levels of homocysteine showed a negative correlation with PON1 activity in patients with AMD. Increased lipid peroxidation and oxidative stress observed in AMD may be associated with decreased PON1. In addition, homocysteine may contribute to decreased serum PON1 activity. Further studies are required to explain the exact role of PON1 in AMD.

\section{References}

Alvares Delfino, V.D., de Andrade Vianna, A.C., Mocelin, A.J., Barbosa, D.S., Mise, R.A. \& Matsuo, T. (2007) Folic acid 
therapy reduces plasma homocysteine levels and improves plasma antioxidant capacity in hemodialysis patients. Nutrition, 23, 242-247.

Axer-Siegel, R., Bourla, D., Ehrlich, R., Dotan, G., Benjamini, Y., Gavendo, S., Weinberger, D. \& Sela, B.A. (2004) Association of neovascular age-related macular degeneration and hyperhomocysteinemia. Am. J. Ophthalmol., 137, 84-89.

Baskol, G., Karakucuk, S., Oner, AO., Baskol, M., Kocer D., Mirza E., Saraymen R. \& Ustdal, M. (2006) Serum Paraoxonase 1 activity and peroxidation levels in patients with age-related macular degeneration. Ophthalmologica, 1, 12-16.

Baskol, G., Karakucuk, S., Oner, A., Ertugrul Mirza, G. \& Kocer, D. (2004) Serum MDA and AOPP levels in age related macular degeneration. Erciyes Medical Journal, 26, 7-11.

Beatty, S., Koh, H., Phil, M., Henson, D. \& Boulton, M. (2000) The role of oxidative stress in the pathogenesis of age-related macular degeneration. Surv. Ophthalmol., 45, 115-134.

Cohen, S.M., Olin, K.L., Feuer, W.J., Hjelmeland, L., Keen, C.L. \& Morse, L.S. (1994) Low glutathione reductase and peroxidase activity in age-related macular degeneration. Br. J. Ophthalmol., 78, 791-794.

Delcourt, C., Cristol, J.P, Tessier, F., Leger, C.L., Descomps, B. \& Papoz, L. (1999) Age-related macular degeneration and antioxidant status in the POLA study. Arch. Ophthalmol., 117, $1384-1390$.

Desmettre, T., Lecerf, J.M. \& Souied, E.H. (2004) Nutrition and age-related macular degeneration. J. Fr. Ophtalmol., 27, 38-56.

Drobek-Słowik, M., Karczewicz, D. \& Safranow, K. (2007) The potential role of oxidative stress in the pathogenesis of the agerelated macular degeneration (AMD). Postepy. Hig. Med. Dosw., 61, 28-37.

Evereklioglu, C., Er. H., Doganay, S., Cekmen, M., Turkoz, Y., Otlu, B. \& Ozerol, E. (2003) Nitric oxide and lipid peroxidation are increased and associated with decreased antioxidant enzyme activities in patients with age-related macular degeneration. Doc. Ophthalmol., 106, 129-136.

Feher, J., Kovacs, B., Kovacs, I., Schveoller, M., Papale, A. \& Balacco-Gabrieli, C. (2005) Improvement of visual functions and fundus alterations in early age-related macular degeneration treated with a combination of acetyl-L-Carnitine, n-3 fatty acids, and coenzyme Q10. Ophthalmologica, 219, 154-166.

Ferretti, G., Bacchetti, T., Masciangelo, S. \& Pallotta, G. (2007) Lipid peroxidation in hemodialysis patients: Effect of vitamin C supplementation. Clin. Biochem., 41, 381-386.

Genser, D., Prachar, H., Hauer, R., Halbmayer, W.M., Mlczoch, J. \& Elmadfa, I. (2006) Homocysteine, folate and vitamin $B_{12}$ in patients with coronary heart disease. Ann. Nutr. Metab., 50, 413-419.

Gocmen, A.Y., Gumuslu, S. \& Semiz, E. (2004) Association between paraoxonase-1 activity and lipid peroxidation indicator levels in people living in the Antalya region with angiographically documented coronary artery disease. Clin. Cardiol., 27, 426-430.

Gocmen, Y.A., Semiz, E. \& Gumuslu, S. (2005) Relationship between paraoxonase-1 (PON1) activity and lipoprotein (a) levels in Turkish coronary artery disease patients living in the Antalya region. Eur. J. Cardiovasc. Prev. Rehabil., 12, 185-186.

Halliwell, B. (1991) Reactive oxygen species in living system: source, biochemistry, and role in human disease. Am. J. Med., 91, 14-22.

Hankey, G.J. \& Eikelboom, J.W. (1999) Homocysteine and vascular disease. Lancet, 354, 407-413.

Harangi, M., Seres, I., Magyar, M.T., Csipo, I., Sipka, S., Valikovics, A., Csiba, L., Bereczki, D. \& Paragh, G. (2008) Association between human paraoxonase 1 activity and intimamedia thickness in subjects under 55 years of age with carotid artery disease. Cerebrovasc. Dis., 25, 122-128.
Ikeda, T., Obayashi, H., Hasegawa, G., Nakamura, N., Yoshikawa, T., Imamura, Y., Koizumi, K. \& Kinoshita, S. (2001) Paraoxonase gene polymorphisms and plasma oxidized low-density lipoprotein level as possible risk factors for exudative agerelated macular degeneration. Am. J. Ophthalmol., 132, 191-195.

Irshad, M. \& Chaudhuri, P.S. (2002) Oxidant-antioxidant system: role and significance in human body. Indian. J. Exp. Biol., 40, 1233-1239.

Isik, B., Ceylan, A. \& Isik, R. (2007) Oxidative stress in smokers and non-smokers. Inhal. Toxicol., 19, 767-769.

Jakubowski H. (1997) Metabolism of homocysteine thiolactone in human cell cultures. Possible mechanism for pathological consequences of elevated homocysteine levels. J. Biol. Chem., 272, 1935-1942.

Jakubowski, H. (2003) Homocysteine thiolactone and S-nitrosohomocysteine mediate incorporation of homocysteine into protein in humans. Clin. Chem. Lab. Med., 41, 1462-1466.

Janel, N., Robert, K., Chabert, C., Ledru, A., Gouédard, C., Barouki, R., Delabar, J.M. \& Chassé, J.F. (2004) Mouse liver paraoxonase-1 gene expression is downregulated in hyperhomocysteinemia. Thromb. Haemost., 92, 221-222.

Kamburoglu, G., Gumus, K., Kadayifcilar, S. \& Eldem, B. (2006) Plasma homocysteine, vitamin B12 and folate levels in agerelated macular degeneration. Graefes Arch. Clin. Exp. Ophthalmol., 5, 565-569.

Kaemmerer, E., Schutt, F., Krohne, T.U., Holz, F.G. \& Kopitz, J. (2007) Effects of lipid peroxidation-related protein modifications on RPE lysosomal functions and POS phagocytosis. Invest. Ophthalmol. Vis. Sci., 3, 1342-1347.

Kamei, M., Yoneda, K., Kume, N., Suzuki, M., Itabe, H., Matsuda, K., Shimaoka, T., Minami, M., Yonehara, S., Kita, T. \& Kinoshita S. (2007) Scavenger receptors for oxidized lipoprotein in age-related macular degeneration. Invest. Ophthalmol. Vis. Sci., 48, 1801-1807.

Leibovitz, B.E. \& Siegel, B.V. (1980) Aspects of free radical reactions in biological systems. Aging. J. Gerontol., 35, 45-56.

Marchegiani, F., Marra, M., Olivieri, F., Cardelli, M., James, R.W., Boemi, M. \& Franceschi C. (2008) Paraoxonase 1: genetics and activities during aging. Rejuvenation Res., 11, 113-127.

Nowak, J.Z. (2006) Age-related macular degeneration (AMD): pathogenesis and therapy. Pharmacol. Rep., 58, 353-363.

Nowak, M., Swietochowska, E., Wielkoszyński, T., Marek, B., Kos-Kudła, B., Szapska, B., Kajdaniuk, D., GłogowskaSzelág, J., Siemińska, L., Ostrowska, Z., Kozioł, H. \& Klimek, J. (2005a) Homocysteine, vitamin B12, and folic acid in age-related macular degeneration. Eur. J. Ophthalmol., 15, 764-767.

Nowak, M., Gnitecki, W. \& Jurowski, P. (2005b) The role of retinal oxygen metabolism in origin of age-related macular degeneration (AMD). Klin. Oczna., 107, 715-718.

Ohira, A., Ueda, T., Ohishi, K., Hiramitsu, T., Akeo, K. \& Obara, Y. (2008) Oxidative stress in ocular disease. Nippon Ganka Gakkai Zasshi, 112, 22-29.

Ozdemir, R., Barutcu, I., Sezgin, A.T., Acikgoz, N., Ermis, N., Esen, A.M., Topal, E., Bariskaner, E. \& Ozerol I. (2004) Vascular endothelial function and plasma homocysteine levels in Behcet's disease. Am. J. Cardiol., 94, 522-525.

Papandreou, D., Mavromichalis, I., Makedou, A., Rousso, I. \& Arvanitidou, M. (2006) Total serum homocysteine, folate and vitamin B12 in a Greek school age population. Clin. Nutr., 25, 797-802.

Papatheodorou, L. \& Weiss, N. (2007) Vascular oxidant stress and inflammation in hyperhomocysteinemia. Antioxid. Redox Signal., 9, 1941-1958.

Stamler, J.S., Osborne, J.A., Jaraki, O., Rabbani, L.E., Mullins, M., Singel, D. \& Loscalzo, J. (1993) Adverse vascular effects of homocysteine are modulated by endothelium-derived relaxing factor and related oxides of nitrogen. J. Clin. Invest., 91, 
308-318.

Seddon, J.M., Ajani, U.A., Sperduto, R.D., Hiller, R., Blair, N., Burton, T.C., Farber, M.D., Gragoudas, E.S., Haller, J. \& Miller, D.T. (1994) Dietry carotenoids, vitamins A, C, and E, and advanced age-related macular degeneration. JAMA., 272, 1413-1421.

Seddon, J.M., Gensler, G., Klein, M.L. \& Milton, R.C. (2006) Evaluation of plasma homocysteine and risk of age-related macular degeneration. Am. J. Ophthalmol., 1, 201-203.

Valko, M., Leibfritz, D., Moncol, J., Cronin, M.T., Mazur, M. \& Telser, J. (2007) Free radicals and antioxidants in normal physiological functions and human disease. Int. J. Biochem. Cell. Biol., 39, 44-84.

Van Leeuwen, R., Klaver, C.C., Vingerling, J.R., Hofman, A. \& de Jong, P.T. (2003) The risk and natural course of age-related maculopathy: follow-up at $61 / 2$ years in the Rotterdam study. Arch. Ophthalmol., 121, 519-526.

Vingerling, J.R., Dielemans, I., Bots, M.L., Hofman, A., Grobbee, D.E. \& de Jong, P.T. (1995) Age-related macular degeneration is associated with atherosclerosis. The Rotterdam Study. Am.
J. Epidemiol., 142, 404-409.

Vingerling, J.R., Hofman, A., Grobbee, D.E. \& de Jong, P.T. (1996) Age-related macular degeneration and smoking. The Rotterdam Study. Arch. Ophthalmol., 114, 1193-1196.

Wiggs, J.L. (2007) Macular degeneration: risk factors for progression. Arch. Ophthalmol., 125, 1264-1265.

Winkler, B.S., Boulton, M.E., Gottsch, J.D. \& Sternberg, P. (1999) Oxidative damage and age-related macular degeneration. Mol. Vis., 5, 32.

Ueland, P.M., Refsum, H., Stabler, S.P., Malinow, M.R., Andersson, A. \& Allen, R.H. (1993) Total homocysteine in plasma or serum: methods and clinical applications. Clin. Chem., 39, 1764-1779.

Upchurch, G.R. Jr., Welch, G.N., Fabian, A.J., Freedman, J.E., Johnson, J.L., Keaney, .JF. Jr. \& Loscalzo, J. (1997) Homocysteine decreases bioavailable nitric oxide by a mechanism involving glutathione peroxidase. J. Biol. Chem., 272, 17012-17017.

Young, R.W. (1998) Solar radiation and age-related macular degeneration. Surv. Ophthalmol., 32, 252-269. 